\title{
Coronavirus Nutritional Care Protocol
}

Mohamed F Madi, Salima Elfagi, Faiza Nouh*, Safia Elramli, Mariam Omar

Nutrition Department - Faculty of Public Health - University of Benghazi

In this protocol, the authors are going to illustrate all steps that should be done for all patients admitted to the hospital as a case infected with the coronavirus. The protocol helps to identify the patient who is at the risk of malnutrition. If malnutrition occurs especially in critically ill patients in the new crown (coronavirus), it will not only reduce respiratory muscle function and increase respiratory muscle weakness but also aggravate immune dysfunction and further worsen the disease. Therefore, carrying out reasonable nutrition assessment and support is important to prevent malnutrition among critically ill patients with new crowns to achieve suitable outcomes. Food safety and hygiene procedures are significant components of the overall hospital nutritional care. These practices deal with all aspects of foods receiving from farm and factory up to serving and food wastage. During the fourteen days of the recovery period, patients need isolation and regular health monitoring. The patient's home should provide equipped for patient isolation and the patients take all necessary precautions.

Keywords: Coronavirus, COVID-19, Nutritional support, Food safety, Discharge.

Copyright @ 2020: This is an open-access article distributed under the terms of the Creative Commons Attribution license which permits unrestricted use, distribution, and reproduction in any medium for non-commercial use (NonCommercial, or CC-BY-NC) provided the original author and source are credited

\section{INTRODUCTION}

Malnutrition in critically ill patients is associated with poor outcomes, including impaired wound healing, higher rates of nosocomial infections, and all-cause mortality. Nutritional status of patients admitted to the intensive care unit (ICU) is influenced by both chronic and acute starvation, but also by the severity of the underlying pathophysiological processes leading to ICU admission. This typically induces a marked catabolic response leading to rapid loss of lean body mass, varying from $5 \%$ in single-organ failure to $25 \%$ in multi organ dysfunction syndrome (MODS), during the first 10 days after ICU admission. Nutritional therapy can improve outcomes associated with malnutrition in critically ill patients. To identify ICU patients most likely to benefit from nutritional support, validated tools are required. Food safety and hygiene is a significant component during food preparation and serving to Covid-19 patients. It is required to use personal hygiene practices against contamination of food, food-contact surfaces, and food packaging and serving. Hospital Nutritional Care is a pathway that supports the detection, prevention and treatment of malnutrition. Key activities to reach these goals are post-acute care includes rehabilitation or palliative services that beneficiaries receive following a stay in an acute care hospital. Depending on the patient's needs, treatment may include a stay in a facility, such as a skilled nursing facility, inpatient rehabilitation facility, or long-term care hospital, or care in the home via a home health agency. Patients with the 2019 coronavirus disease (COVID-19) have different degrees of psychological pain, such as anxiety and depression, which may relate to their prognosis. Psychological intervention can be conducted in different ways to improve psychological pain and improve the treatment effect. All the patients in should receive comprehensive psychological intervention, including telephone psychological counseling (active and passive, self-adjustment of written materials and one-to-one psychological crisis intervention. When deciding on criteria for hospital discharge of COVID-19 patients, health authorities should take into account several factors such as the existing capacity of the healthcare system, laboratory diagnostic resources, and the current epidemiological situation. In this protocol, the authors are going to illustrate all steps that should be done for all patients admitted to the hospital as a case infected with the coronavirus. The protocol helps to identify the patient who is at the risk of malnutrition. If malnutrition occurs especially in critically ill patients in the new crown (coronavirus, it will not only reduce respiratory muscle function and increase respiratory muscle weakness but also aggravate immune dysfunction and further worsen the disease. Therefore, carrying out 
reasonable nutrition assessment and support is important to prevent malnutrition among critically ill patients with new crowns to achieve suitable outcomes. Food safety and hygiene procedures are significant components of the overall hospital nutritional care. These practices deal with all aspects of foods receiving from farm and factory up to serving and food wastage. During the fourteen days of the recovery period, patients need isolation and regular health monitoring. The patient's home should provide equipped for patient isolation and the patients take all necessary precautions (e.g. single room with good ventilation, face-mask wear, reduced close contact with family members, separate meals, good hand sanitation, and no outdoor activities). All these practices protect family members and the community from infection and further spread of SARS-CoV-2 [1, 7]. The aim of this protocol is to improve patient's nutritional status, aid immune system function, enable weight maintenance or gain, and facilitate transition off nutrition supported by applying a comprehensive food protocol to suppress coronaviruses.

\section{METHODOLOGY}

Google Scholar search engine was used to gather information relating to nutritional management guideline for COVID-19 patients. The studies were written in English. The period of literature age has extended from the inception of the search engine to the first of April 2020. The search generated about 39 sources, of which 19 sources were used. These 19 articles were considered relevant because they answered the objectives of the review. The library databases such as PubMed and MEDLINE were also used during the study.

\section{Nutrition Screening}

Nutrition risk screening is the first step in identifying patients at risk for malnutrition. It is recommended to select a short, valid and reliable form for emergency care. The suitable tool should be used for COVID - 19 patient admitted to the words is NRS as shown in figure one [2,3].

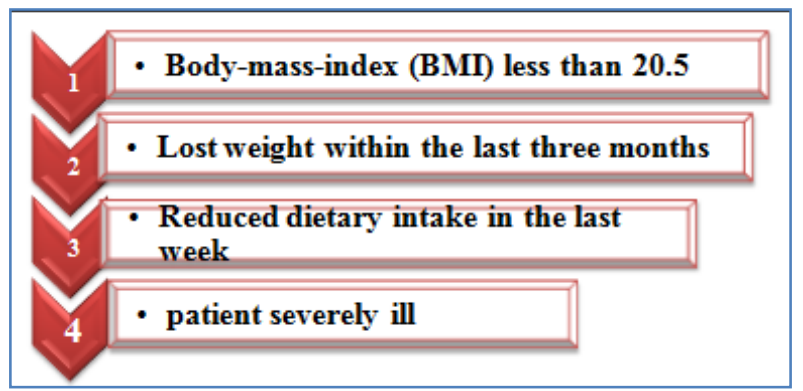

Fig-1: Prescreening Test

If one of this steps with positive mark, this mean the patient at nutritional risk, so the final screening must be done to predict the degree of malnutrition. The negative mark for all steps, this mean patient will be subject to rescreening weekly or 3 days according to severity of disease. Most important of final screening are nutritional statues score and Stress metabolism (severity of the disease) score. According to (Table 1) NRS 2002 score $\geq 3$ points, suggesting that there is nutritional risk, and nutrition intervention is needed; NRS 2002 score $\geq 5$ points suggesting that patients have higher nutritional risks and it should be as early as possible give nutritional support. The nutritional status of critically ill patients with COVID - 19 may change rapidly. Table one and two show the screening steps $[4,5]$.

Table-1: Screening Steps (NRS 2002) Form

\begin{tabular}{|c|c|c|}
\hline Nutritional status & score & Stress metabolism (severity of the disease) \\
\hline None & 0 & None \\
\hline \multirow{2}{*}{$\begin{array}{l}\text { Mild: Weight loss }>5 \%-3 \text { months } \\
\text { OR } \\
50-75 \% \text { of the normal food intake in the last week }\end{array}$} & \multirow[t]{2}{*}{1} & Mild stress metabolism \\
\hline & & $\begin{array}{l}\text { Mobile patient } \\
\text { Increased protein requirement can be covered with oral nutrition } \\
\text { Hip fracture, chronic disease especially with complications e.g., } \\
\text { liver cirrhosis, COPD, diabetes, cancer, chronic hemodialysis }\end{array}$ \\
\hline $\begin{array}{l}\text { Moderate: Weight loss }>5 \% \text { in } 2 \text { months } \\
\text { OR BMI } 18.5-20.5 \mathrm{~kg} / \mathrm{m}^{2} \text { and reduced general } \\
\text { condition } \\
\text { OR } 25-50 \% \text { of the normal food intake in the last week }\end{array}$ & 2 & $\begin{array}{l}\text { Moderate stress metabolism: patient is bedridden due to illness. } \\
\text { Highly increased protein requirement, may be covered with } \\
\text { Stroke, hematologic cancer, severe pneumonia, extended } \\
\text { abdominal surgery }\end{array}$ \\
\hline $\begin{array}{l}\text { Sever: Weight loss }>5 \% \text { in } 1 \text { month OR BMI }<18.5 \\
\mathrm{~kg} / \mathrm{m}^{2} \text { AND reduced general condition OR } 0-25 \% \text { of } \\
\text { the normal food intake in the last week }\end{array}$ & 3 & $\begin{array}{l}\text { Severe stress metabolism } \\
\text { Patient is critically ill (intensive care unit) } \\
\text { Very strongly increased protein requirement can only be } \\
\text { achieved with (par)enteral nutrition } \\
\text { APACHE-II }>10 \text {, bone marrow transplantation, head traumas }\end{array}$ \\
\hline \multicolumn{2}{|l|}{ Total (A) } & Total (B) \\
\hline \multicolumn{3}{|c|}{ Age: $<70$ years: $0 \quad * * * \quad \geq 70$ years: 1} \\
\hline \multicolumn{3}{|c|}{ TOTAL $=(\mathrm{A})+(\mathrm{B})+$ Age } \\
\hline & & \\
\hline
\end{tabular}


Nutritional risk assessment must be also done on all critically ill patients. Malnutrition in intensive care unit (ICU) patients is associated with adverse clinical outcomes. Traditional scoring systems cannot be used for screening in mechanically ventilated (MV) patients, so the appropriate nutritional assessment tool in MV patients is NUTRIC score (modified without ILK-6). This type of screening should be applied by ICU multidisciplinary team. If patients found to have a risk during screening should be precede to assessment $[8,9]$.

Table-2: The NUTRIC without IL-6

\begin{tabular}{|l|c|c|}
\hline Variable & Range & Points \\
\hline \multirow{4}{*}{ Age } & $<\mathbf{5 0}$ & $\mathbf{0}$ \\
\cline { 2 - 3 } & $\mathbf{5 0}$ to $<\mathbf{7 5}$ & $\mathbf{1}$ \\
\cline { 2 - 3 } & $\geq \mathbf{7 5}$ & $\mathbf{2}$ \\
\hline \multirow{4}{*}{ APACHE II } & $<\mathbf{1 5}$ & $\mathbf{0}$ \\
\cline { 2 - 3 } & $\mathbf{1 5}$ to $<\mathbf{2 0}$ & $\mathbf{1}$ \\
\cline { 2 - 3 } & $\mathbf{2 0 \text { to } 2 8}$ & $\mathbf{2}$ \\
\cline { 2 - 3 } & $\geq \mathbf{2 8}$ & $\mathbf{3}$ \\
\hline \multirow{4}{*}{ SOFA } & $<\mathbf{6}$ & $\mathbf{0}$ \\
\cline { 2 - 3 } & $\mathbf{6}$ to $<\mathbf{1 0}$ & $\mathbf{1}$ \\
\cline { 2 - 3 } & $\geq \mathbf{1 0}$ & $\mathbf{2}$ \\
\hline Number of co-morbidities & $\mathbf{0}$ to $\mathbf{1}$ & $\mathbf{0}$ \\
\cline { 2 - 3 } & $\geq \mathbf{2}$ & $\mathbf{1}$ \\
\hline \multirow{2}{*}{$\begin{array}{l}\text { Days from hospital to ICU } \\
\text { admission }\end{array}$} & $\mathbf{0}$ to $<\mathbf{1}$ & $\mathbf{0}$ \\
\cline { 2 - 3 } & $\geq \mathbf{1}$ & $\mathbf{1}$ \\
\hline Sum of points & Category & Explanation \\
\hline $5-9$ & High score & Associated with worse clinical outcome (mortality, ventilation) \\
\hline $0-4$ & Low score & The patients have a low malnutrition risk \\
\hline
\end{tabular}

\section{Nutrition Assessment}

Subjective global assessment (SGA) is the gold standard for diagnosing malnutrition. SGA is a simple bedside method used to diagnose malnutrition and identify those who would benefit from nutrition care. The assessment includes taking a history of recent intake, weight change, gastrointestinal symptoms and a clinical evaluation. Figure two shows of SGA form. For each component of the scored SGA, scores are awarded depending upon the impact of the symptoms on the nutritional status. A higher score indicates a greater risk of malnutrition. The global rating of A (Well nourished), B (Moderately malnourished or suspected malnourishment) or C (Severely malnourished) were done taking into account the various components (weight, nutrient intake, nutrition impact symptom, functioning and physical examination) as shown in appendix II and as recommended by reserahcers. Once the entire PG-SGA is completed, a total score is summed up that then determines how aggressive the nutrition intervention should be. Additive score is used to define specific nutrition interventions, including patient and family education, symptom management including pharmacologic intervention and appropriate nutrition intervention (food, nutritional supplements, enteral or parenteral triage). Scores 0- means no intervention required at this point. Scores 2-3 means patient and family education by the dietician, nurse or other clinician with pharmacological intervention as indicated by symptoms (Box 3 ) and laboratory values as appropriate. Scores 4-8 means requires intervention by dietician, in conjunction with nurse or physician as indicated by symptom survey box 3 . Scores $\geq 9$ indicates a critical need for improved symptom management and/or nutrient intervention options [4-8]. 


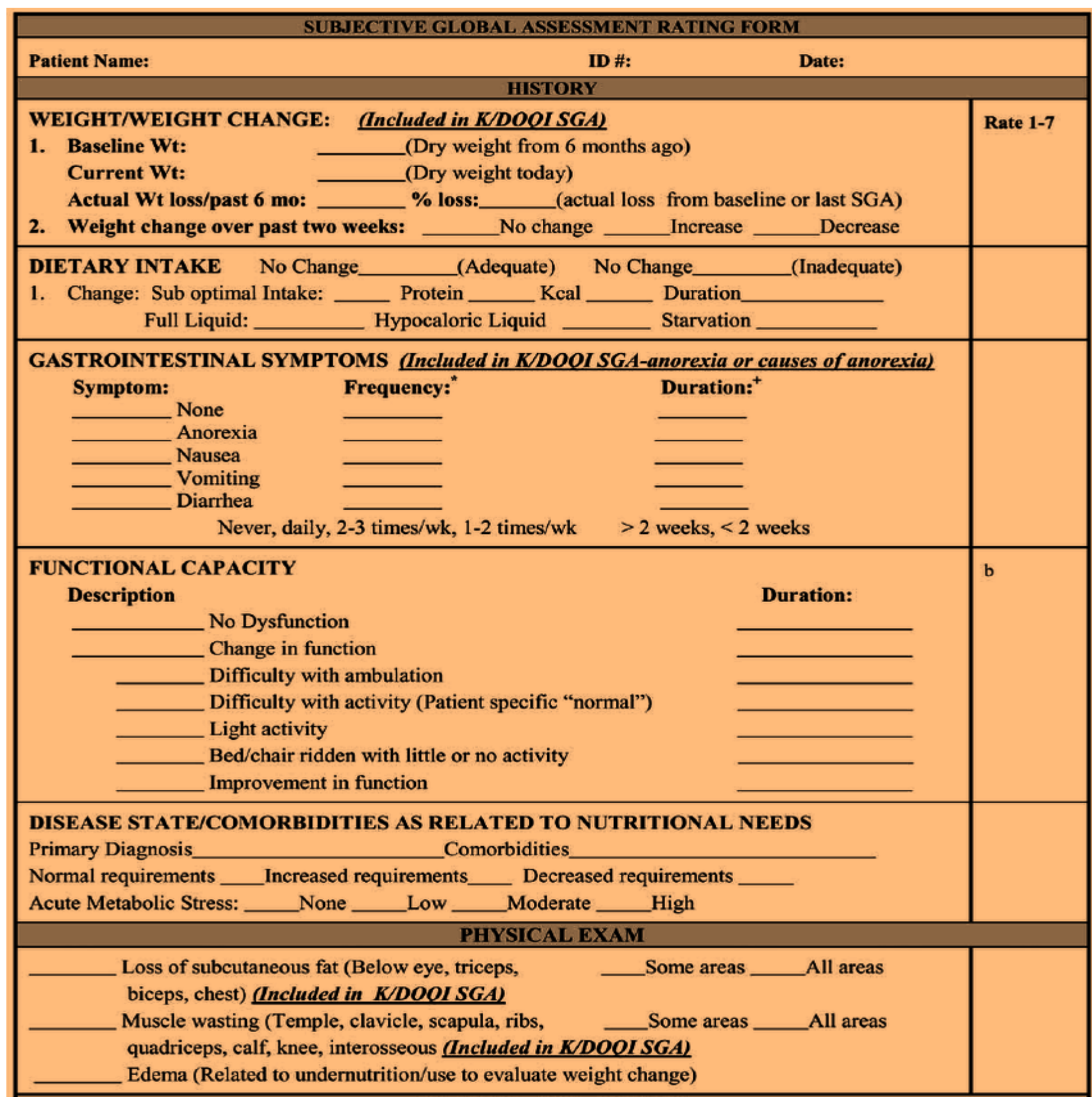

Fig-2: SGA Form

\section{Nutritional Care Pathway}

According to ASPEN Standards of Care for Hospitalized Patients, All patients that admitted to the hospitals should undergo to these steps shown in Figure three to know their nutritional status, by dietitians in cooperate with multidisciplinary team. The first step is screening step. If the patient admitted to the ICU with adequate food intake that means the dietitian needs to rescreening using (NUTRIC score or NRS 2002) in 3-5 days. If the patient admitted to the ICU with inadequate food intake that means the dietitian needs to determine the nutrition risk using (NUTRIC score or NRS 2002). The second step for risk patinas is the assessment step. If the patient is not at high nutrition risk or malnourished specialized nutrition therapy is not required and rescreening in 2-3 days if remains in ICU. If the patient is at high nutrition risk or malnourished so the dietitian needs to check that is early enteral nutrition is feasible. If early enteral nutrition is not feasible, dietitian should initiate PN as early as feasible. If early enteral nutrition is feasible; dietitian needs to check whether or not the patient is hemodynamically stable. If the patient is not hemodynamically stable, dietitian should withhold enteral feedings until the patient is fully resuscitated and/or stable. On the other hand, If the patient is hemodynamically stable, dietitian may Begin EN and advance toward goal over 24-48 hours (goal of $>80 \%$ of estimated energy/protein requirements within 48-72 hours) (Refer to Nutrition Assessment). Energy calculation for COVID-19 patients is shown in figure 3 . 
Nutritional support should be started as soon as possible after fluid resuscitation is completed and hemodynamic is basically stable. Feeding should start at a low dose (initial stage of stress such as infection) and reach the energy target amount within 3 to 7 days. Nutritional supply should not exceed $70 \%$ of the target amount in first days. After stabilization, the energy intake should be gradually increased to the target amount within 3 to 7 days. High-quality protein and branched chain amino acids BCAA such as whey protein and other animal proteins, are highly recommended to use. So that its proportion reaches $50 \%$ of the total protein, it is more beneficial to which can not only significantly inhibit muscle breakdown, but also improve insulin resistance and enhance the efficacy of interferon [8-12].

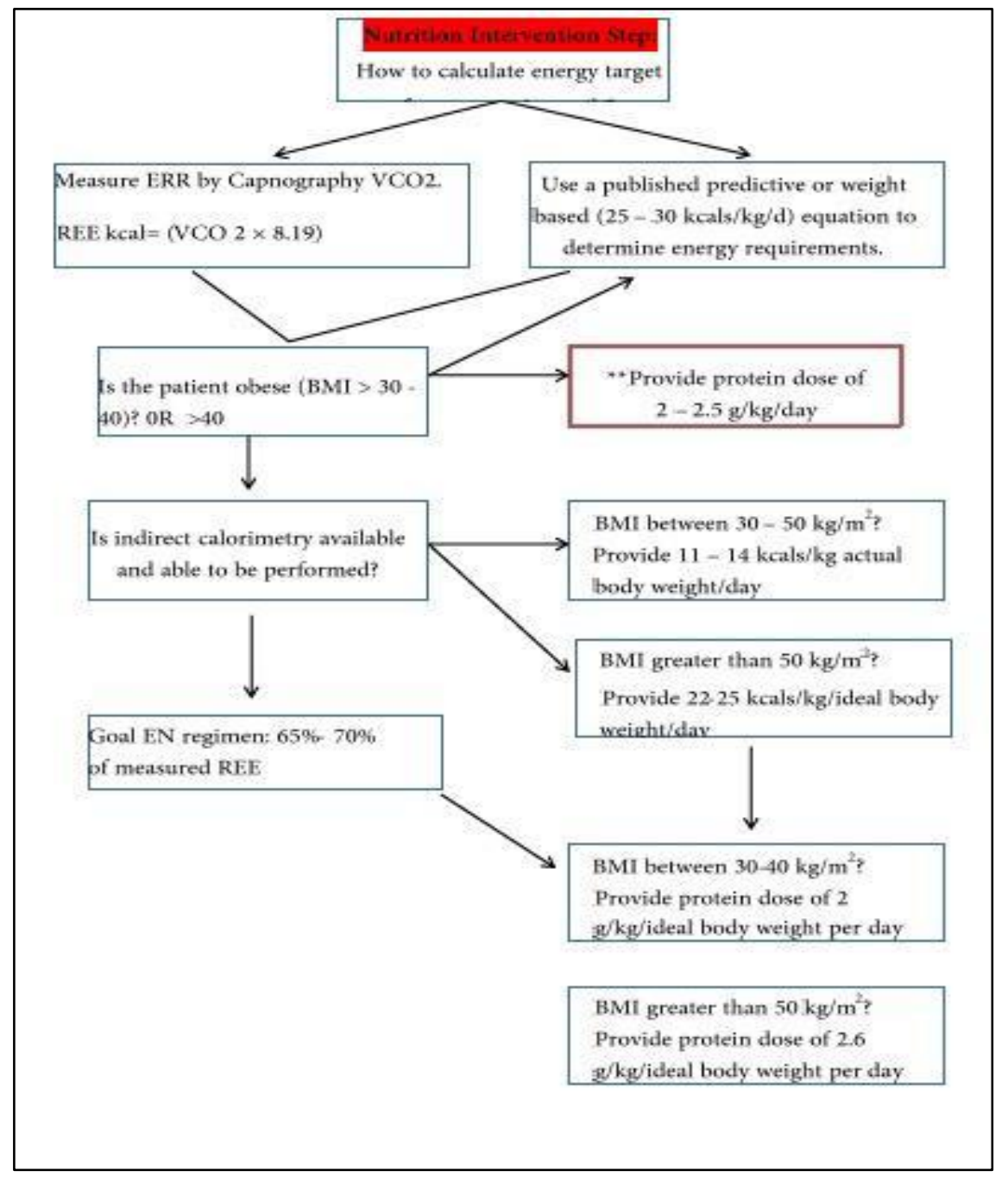

Fig-3: Energy calculation for COVID-19 patients

The minimum amount of fluid for critically ill patients is set to meet the main nutrient requirements, within limits. For every $1{ }^{\circ} \mathrm{C}$ increase in body temperature, supplement $3 \sim 5 \mathrm{~mL} / \mathrm{kg}$ (calculated as 4 $\mathrm{mL} / \mathrm{kg}$ ). Most patients with new crown crises have pulmonary edema and fluid accumulation. While maintaining fluid balance, it is even more necessary to prevent excess fluid, especially intravenous fluid volume. The new crown critically ill patients, should a conventional supplementation, such as vitamin B1, vitamin $\mathrm{C}$, selenium, zinc, as the reference standard normal recommended nutrient intake. It is suggested that hypo caloric dosing with adequate protein initially is used over the first week of hospitalization. It is recommended to use $20 \mathrm{kcals} / \mathrm{kg} /$ day or $80 \%$ estimated energy needs, $\leq 1.2 \mathrm{~g}$ protein $/ \mathrm{kg} /$ day. Withhold or limit soybean oil based intravenous fat emulsion during the first week to a maximum of $100 \mathrm{~g} /$ week. Target blood glucose range should be $140-180 \mathrm{mg} / \mathrm{dL}$. It is suggested that parenteral glutamine supplementation not be routinely used. Standardized commercially available PN formulations have no advantage compared to compounded PN admixtures. It is suggested to reduce PN energy as EN tolerance improves; discontinue PN when patient is receiving $>60 \%$ of target energy requirements from EN [4]. 


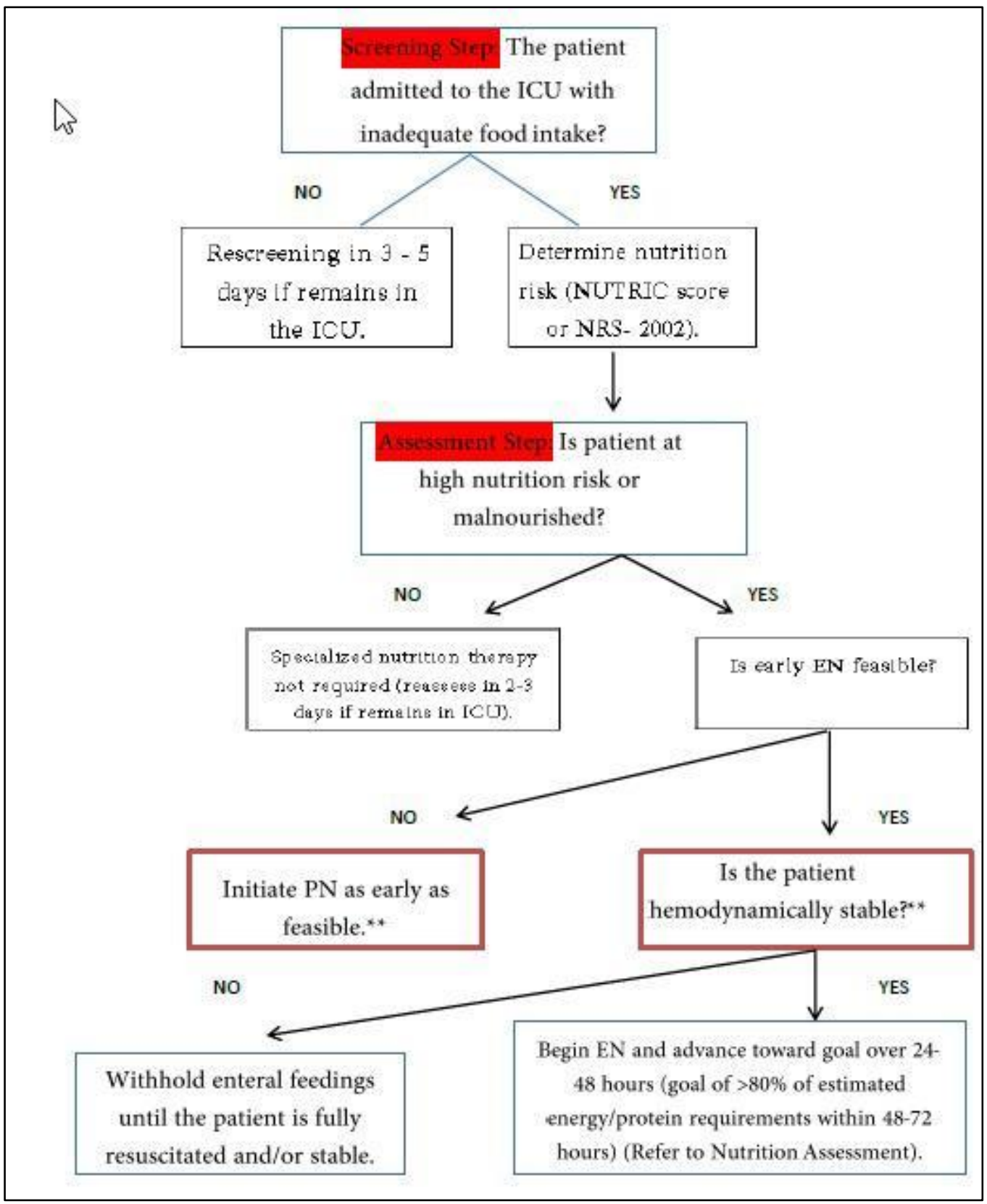

Fig-4: Nutritional Support Therapy Algorithm

\section{Food Safety}

Generally, hospitals kitchens follow food safety requirements to control covid -19 . Specifications include temperature at receipt; ensure the food is safe and unadulterated by covid -19 . Food Safety is defined as the condition and practices that preserve foods quality to prevent contamination and illness of covid -19. Food hygiene is defined as the conditions and measures that ensure the safety of food from production to consumption of covid -19. Figure four shows Food Management Diagram during covid -19 pandemic within hospital kitchen. Food management in Hospital Kitchen is complying with food hygiene and food standards. Food safety management components are the suppliers you use, how you trace the food you prepare, how to trace the food serving to patients and how to transport food. Food prepared by hospital kitchen should provide all required nutritional information such as ingredients, nutritive values any additives. The meal label should include: ingredient statement, the name and place of business of the food manufacturer, packer, or distributor, net quantity of contents, allergen information. Hospital kitchen management during Covid-19 pandemic consists of menu planning, quality control, financial management, personal management, food management, equipments management, area management, and row material management $[13,16]$. 


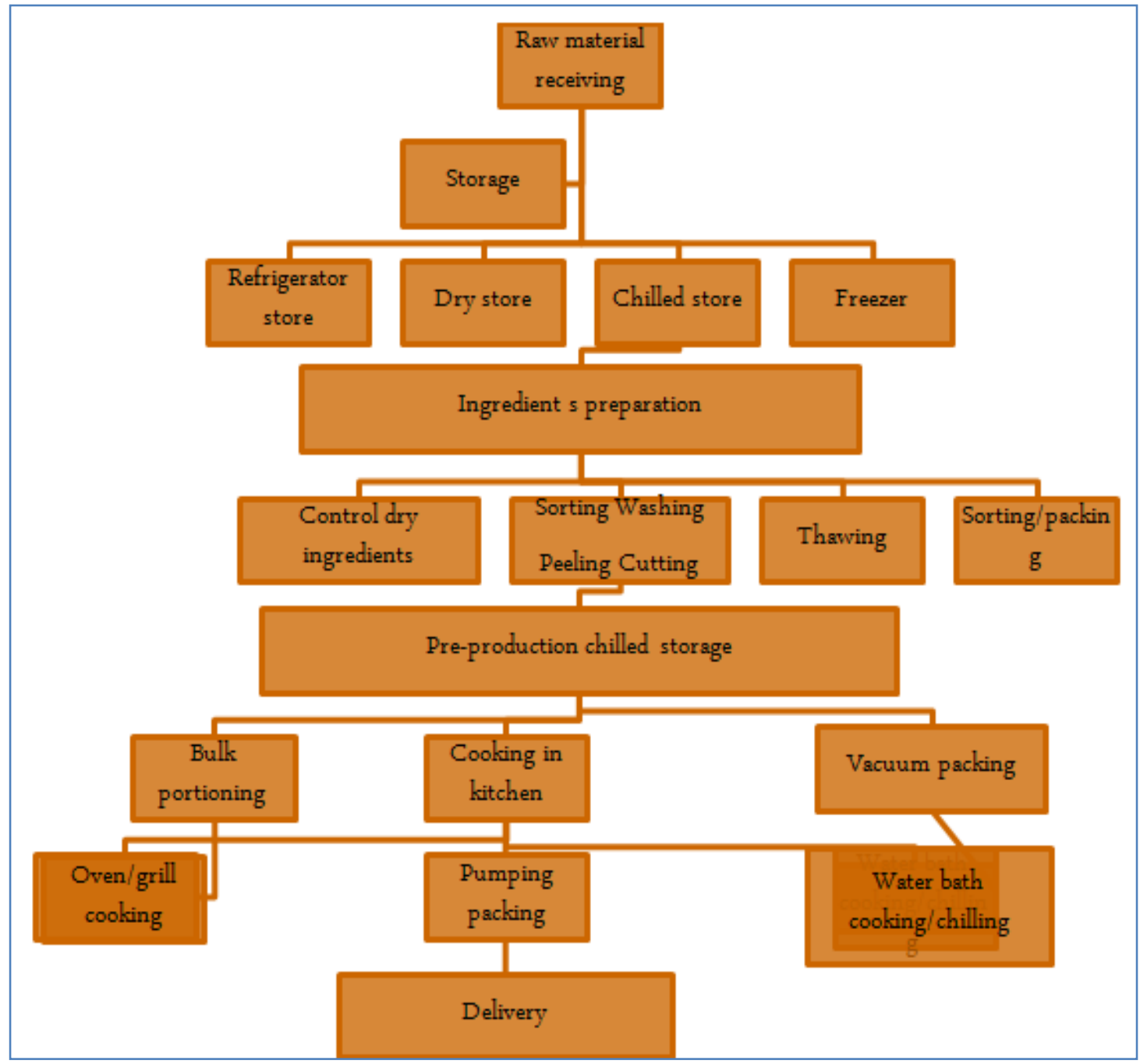

Fig-5: Food Management Diagram during covid -19 pandemic

\section{Food Hygiene}

Good food hygiene is essential to make sure that the food you serve is safe to eat. It helps prevent food poisoning. Good food hygiene to prevent covid -19 consists of personal hygiene, food hygiene, and kitchen hygiene. The four main things to remember for good hygiene are the 4Cs; Cleaning, Cooking, Chilling and Cross-contamination. The 4 C's Concept during covid -19 pandemic; C - good hygiene practice prevent Cross-contamination, C - Effective, Cleaning remove harmful covid-19 and stop spread, C - Effective Chilling prevent harmful organism multiplication, and $\mathrm{C}$ - thorough Cooking kills organism. Clean and disinfect food areas and equipment between different tasks, especially after handling raw food. If some food spill in hospital kitchen, it should be cleared up straight away and clean the surface thoroughly. It is recommended to use cleaning and disinfection products that are suitable for the job and follow the manufacturer's instruction. It is not recommended to let food waste build up. Dispose of food waste suitably. It is recommended to use a cleaning schedule to make sure that surfaces and equipment are cleaned when they need to be. It can also help to stop cleaning products being wasted or used incorrectly [13].

\section{Hospital Kitchen Cleaning Schedule}

Work out what needs cleaning or disinfecting every day, or more than once a day, and what needs cleaning less frequently. Your schedule should show: what needs to be cleaned, what needs to be disinfected, how often it needs to be done, how the cleaning/disinfecting should be done. It is a good idea to include cleaning instructions showing: cleaning procedures, what cleaning products should be used, how the products should be used, including how much they should be diluted and how long they should be left in contact with the surface, following the manufacturer's instructions, how the products should be stored - in a special place, not in food areas. Figure five shows a flow chart of hospital kitchen work. Physical facilities divided into two components; peripheral components such as 
collection of diet demand, distribution of diet. Central component consists of administration area, cooking area, preparation area, services area, receiving area, dry ration storage, gold rooms for perishable area, garbage collection area, toilets and finally washing area which consists of dish washing area and trolley washing area.

\section{Cooking safely}

The following types of meat should thoroughly cook; poultry, for example chicken or turkey, duck and other fowl, products made from minced meat, such as burgers, sausages and kebabs, kidneys, liver and other types of offal Before you serve them, check that: they are steaming hot all the way through, any juices run clear, there's no pink or rare meat inside, make sure the meat surface is properly cooked and sealed to kill any bacteria, even if the middle of the meat is still pink. During cooking, heat energy transfers into and breaks down proteins in the food. The meat changes colour from pink to brown or to white. Its texture changes too. Cooking also causes the proteins in bacteria to break up so they no longer function and the bacteria die. This is why cooking removes the risk from harmful bacteria that are in some food. Bacteria usually grow in the 'Danger Zone' between $8^{\circ} \mathrm{C}$ and $60^{\circ} \mathrm{C}$. Below $8^{\circ} \mathrm{C}$, growth is stopped or significantly slowed down. Above $60^{\circ} \mathrm{C}$ the bacteria start to die. Time and temperature are both important because proteins need to be heated up for a long enough time for them all to be broken down. Standard advice is to cook food until it has reached $70^{\circ} \mathrm{C}$ and stayed at that temperature for 2 minutes. The other time and temperature combinations are: $60^{\circ} \mathrm{C}$ for 45 minutes, $65^{\circ} \mathrm{C}$ for 10 minutes, $70^{\circ} \mathrm{C}$ for 2 minutes, $75^{\circ} \mathrm{C}$ for 30 seconds and $80^{\circ} \mathrm{C}$ for 6 seconds. Regarding reheating food; It is every important to reheat food properly to kill harmful organisms that may have grown since the foods was cooked. Reheating means cooking again, not just warming up. Always reheat food until it is steaming hot all the way through. It is recommended that only reheat the food once [13-16].
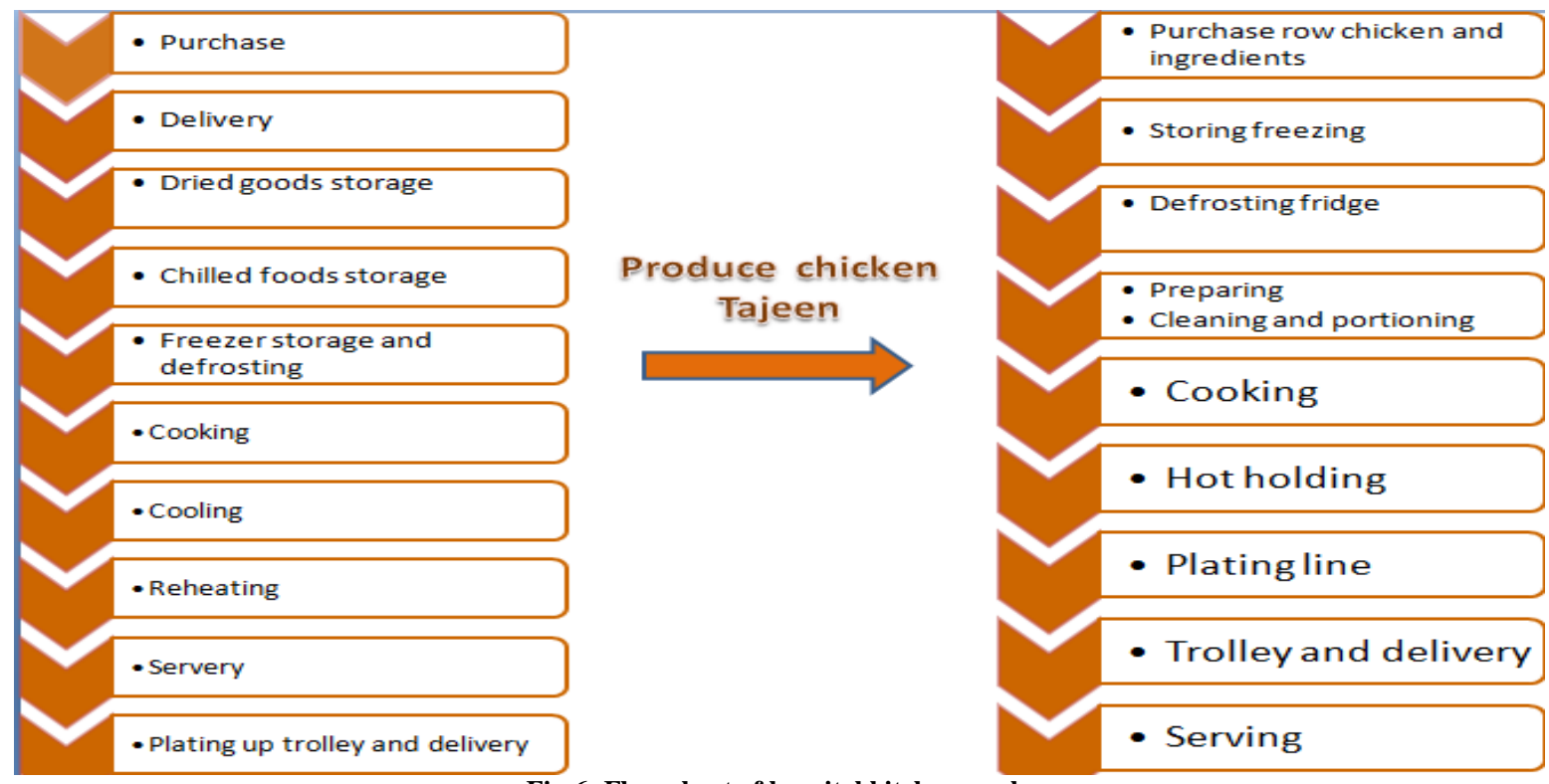

Fig-6: Flow chart of hospital kitchen work.

\section{Food monitoring list: A-O list}

It is consists of hazard analysis form, approved hospital suppliers list, delivery check record, fridge temperature checks, freezer temperature checks, defrosting temperature/ time checks, cooking temperature records, servery temperature record, trolley temperature records, training records, cleaning schedule, pest control records, probe thermometer maintain records, internal audit and HACCP planner. Figure six shows health recipes example[15].

\section{Review Employee Health Policies and Procedures}

It is recommended to prohibit food workers from working in food establishments while sick. It is recommended to review your sick leave policies and expand upon paid leave options. It is recommended to offering paid sick leave will help mitigate the economic impacts. It is recommended to talk with workers about employee health requirements. Workers that are possibly sick with the symptoms matching COVID-19 should stay home. Employees with family members/caregivers with symptoms matching COVID-19 should also stay home. Food workers and managers with coughing, shortness of breath, fever, or other symptoms of illness should not return to work until they are symptom-free. Current guidance is to stay home until at least 72 hours after symptoms have gone away. This may be altered by medical diagnosis, local health direction, changing community conditions, or other factors. Employers are encouraged not to require employees to provide a doctor's note to return to work, because doing so will burden the medical system [12-14]. 
Food preparation and Hand Hygiene

COVID-19 is, is susceptible to EPA-registered sanitizers and disinfectants. It is recommended that only use sanitizers registered with EPA as a sanitizer. It is recommended that read the sanitizer label and follow usage directions. It is recommended that measure the concentration of the sanitizer to make sure the active ingredient is available. The EPA has a list of registered sanitizers labeled for use against the novel covid-19. There may be additional disinfectants that meet the criteria following the product label use directions for enveloped viruses. These disinfection concentrations not allowed for use on food dishes and utensils. It is recommended that be sure to follow the label directions for food contact surfaces. It is recommended that be sure to wash and rinse equipment of visible dirt or debris before sanitizing. Sanitizers work better on clean surfaces. Food utensils, cutting boards, and serving must be washed, rinsed, and sanitized often throughout the day. It is recommended that bee sure dishes are properly washed and sanitized with chemicals or a high-heat dishwasher after each patient's use. All non-food contact surfaces, such as equipment, counters, menus, tables, chairs, bathrooms, and doors should be cleaned of spills as needed and sanitized often. Wash, rinse, and sanitize non-food contact surfaces that employee and customers touch throughout the day. It is recommended that to help protect workers and patients, increase the frequency of cleaning and sanitizing patients-access areas. It is recommended that use a separate wiping cloth and sanitizing solution when sanitizing the front of patient's access areas. It is recommended that consider removing decorative objects, papers, and other unneeded materials. It is recommended that sanitize outside of condiment containers and other items frequently handled such as doorknobs, backs of chairs, faucet handles, tabletops, and menus at least daily. It is recommended that be wash, rinse, and sanitize tongs and other utensils in self-service areas often throughout the day and provide alcohol-based hand antiseptic rubs at the entrance to the facility. It is recommended that wash hands frequently and thoroughly with soap and water for at least 20 seconds. All washing station should stock with soap, paper towels, and warm, running water. It is recommended that always using a barrier such as tongs, gloves, or other utensil to prevent direct hand contact with food. The virus is likely to be inactivated by proper cooking temperatures. It is important to use gloves or other barriers to prevent touching foods that will not be fully cooked. It is recommended that all employees cover coughs and sneezes with a tissue. If a tissue is not available, employees can sneeze into their shirt sleeve, but not into their hands. It is recommended that discard tissues into a lined garbage bin. It is recommended that wash hands immediately with soap and water after each cough or sneeze. It is recommended that remind employees to avoid touching eyes, nose, and mouth to help slow the spread of germs. Food workers should wash their hands whenever they touch their eyes, nose, or mouth. It is recommended that be providing tissues, no-touch waste bins. It is recommended that using alcohol-based hand antiseptic rubs (at least $60 \%$ ethyl alcohol) in patients' areas. Hospital Kitchen Environmental components are adequate ventilation, gas pipeline, garbage disposal, enough light, water supply, sold stainless flooring, steam supply. All these components should follow the food safety and food hygiene guidelines [10-15].

\section{Core Objectives of Catering Department}

The core objectives include control catering budget and contract: food, beverages and snacks, choose and order ingredients, and develop recipes; menu's taking into consideration dietetic advice, patient's age, culture, and medical condition. Other objectives include prepare food to quality approved standards, deliver food to wards, patients and staff restaurants. Also, they serve food to patients at ward level (Nurses/ Hostesses), provide snacks. Further significant function include maintain and supervise food hygiene at all times. Finally they control cost and monitor waste. Figure seven shows hospital catering process. Hospital kitchen Performance indicators include Number of complaints on food received, number of cases of food poising, instance of false diet disribustion, non/ inadequte serving complian, wastage incidance, pest and rodents, feedback form, and interview at the time of dischraeg[13].

\section{Food wastage}

The level of food wastage affects catering services coast. Food wastes occur at any or all of the following stages: production, unserved meals, ward level, patients' uneaten food, and staff dining room. The best control over food waste are when wastage levels are regularly monitored, wastage target are stand, wastage levels and values measured against theses target. Measurement to avoid food wastage include using different sizes of trays, plated meal services, use menu card services "meal on patient's choice", regular check of all admission and discharge and nurses write the notes "connection between ward and kitchen[14]. 


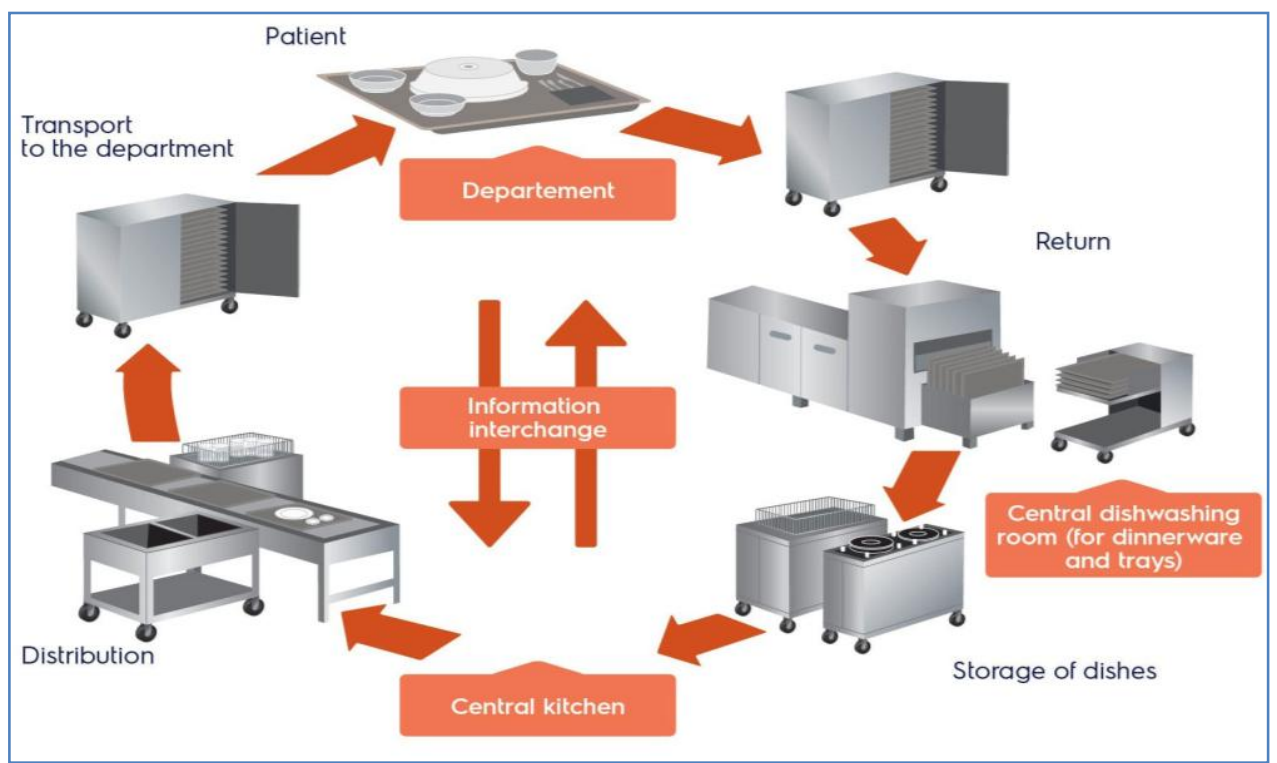

Fig-7: Hospital catering process

\section{Discharge Planning and Auditing: Monitoring and Practice}

Hospital discharge describes the point at which inpatient hospital care ends, with ongoing care transferred to other primary, community or domestic environments. Reflecting this, hospital discharge is not an end point, but rather one of multiple transitions within the patient's care journey. The organization and provision of this transitional care typically involves multiple health and social care actors, who need to co-ordinate their specialist activities so that patients receive integrated and, importantly, safe care. The inherent complexity of co-coordinating a large number of actors, often based in distinct organizations, leads to the view that hospital discharge can be a vulnerable, time-dependent and high-risk episode in the patient pathway. Figure eight shows how to prevent re-infection in discharged COVID-19 patients [17, 18].

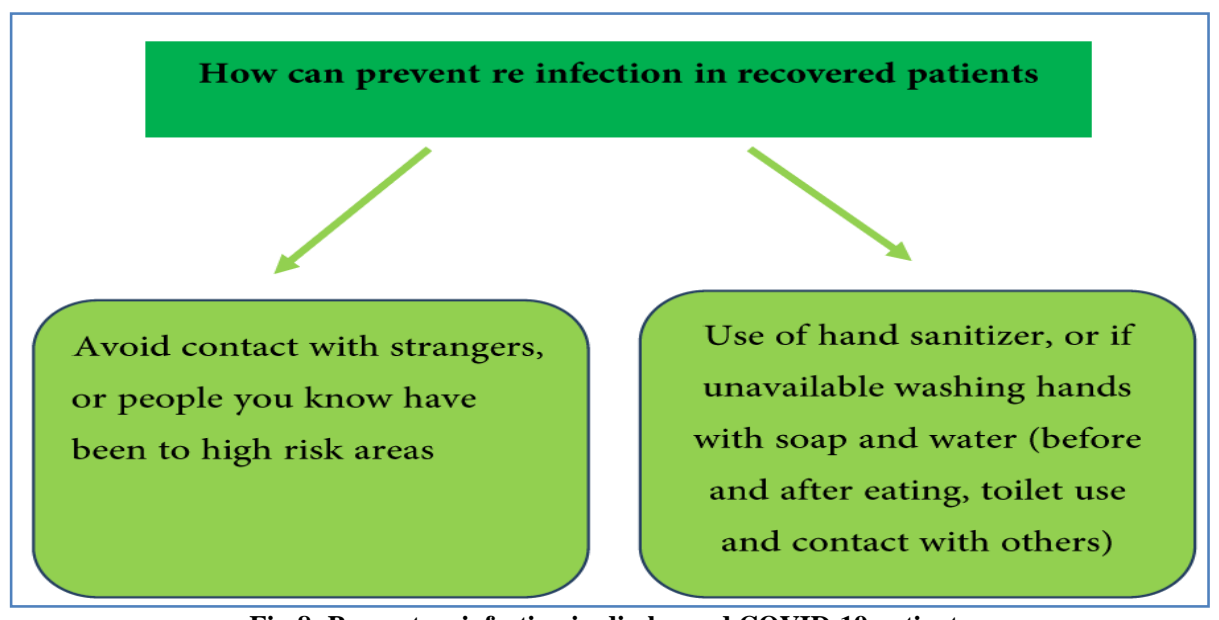

Fig-8: Prevent re-infection in discharged COVID-19 patients

Advice for older adults and people with pre-existing conditions include that when patients have visitors to, exchange "1 meter greetings", like a wave, nod, or bow is recommended. It is recommended that to ask visitors and those who live with to wash their hands. It is recommended that regularly clean and disinfects surfaces in home, especially areas that people touch a lot. If someone patients live with isn't feeling well (especially with possible COVID-19 symptoms), limit shared spaces. If patients become ill with symptoms of COVID-19, It is recommended to contact healthcare provider by telephone before visiting healthcare facility. It is recommended that to make a plan in preparation for an outbreak of COVID-19 in the community. It is recommended that when patients go out in public; follow the same preventative guidelines as patient would at home. It is recommended that to stay up to date using information from reliable sources [17-19]. 


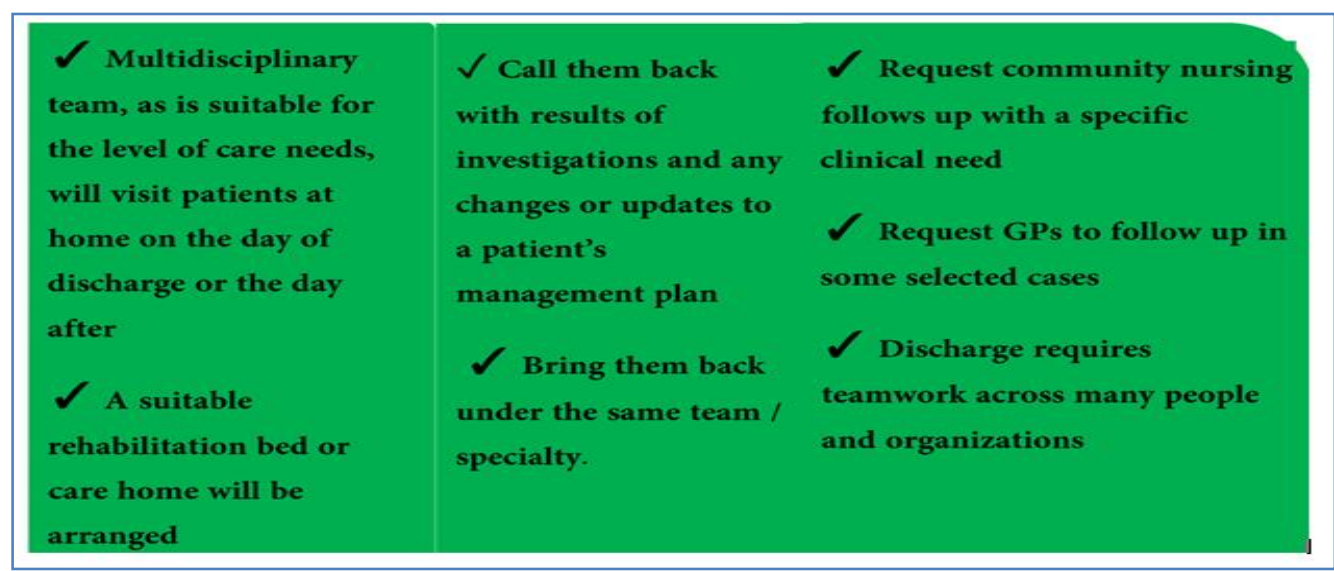

Fig-9: Discharge Guidline for COVID-19 Patients

Improved 'discharge planning' has been a consistent recommendation of policy and research. Over the last two decades, the precise form of discharge planning guidelines has varied to reflect wider health and social care reforms, changing economic imperatives and emerging concerns about care quality. Furthermore, they have been developed both locally, by individual care organizations, and nationally. In 2010, the Department of Health published its new discharge workbook, Ready to Go? Planning the Discharge and Transfer of Patients from Hospital and Intermediate Care, which outlined 10 'steps' to ensuring a timely, safe and patient-centered transition from hospital, including: effective communication with individuals and across settings, alignment of services to ensure continuity of care, efficient systems and processes to support discharge and care transfer, clear clinical discharge management plans, early identification of discharge or transfer date, identified named lead co-coordinators, organizational review and audit and 7-days-a-week proactive discharge planning[17,18].

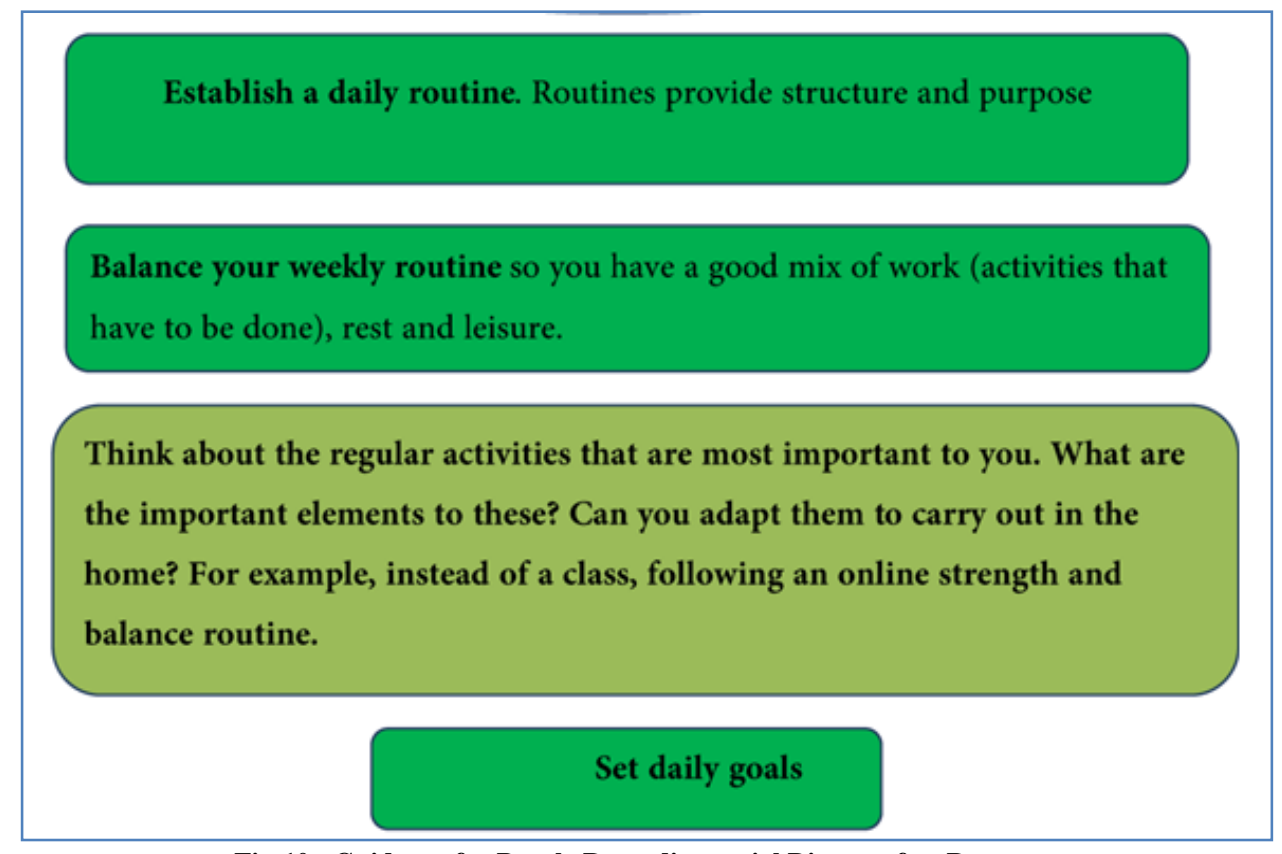

Fig-10: Guidance for People Regarding social Distnce after Recovery

As these policies suggest, a number of specialist roles and activities are promoted as supporting the integration of different agencies. A longstanding objective has been to promote the use of MDTs in discharge planning. These are normally organised as formal, usually weekly, meetings between relevant health and social care specialists with the aim of supporting timely communication, inclusive decision-making and continuity of care. Research often describes MDTs as comprising a core team including the named doctor and nurse, occupational therapists (OTs) and physiotherapists (PTs), and representatives from community and social care agencies, as well as family representatives, GPs and other specialist therapists. According to Bull and Roberts, MDTs help break down barriers between professional groups and foster a sense 
of common purpose and trust. Importantly, MDTs provide an opportunity for communication, first between professionals, second with patient and family, and third with community health-care providers. Furthermore, MDTs can help make clear the lines of responsibility for different tasks and create opportunities for individuals to take the lead in co-coordinating the planning process. In practice, however, convening all representatives for individual patients can be challenging in terms of time or resources. A further initiative has been the introduction of discharge co-coordinators [18,19].

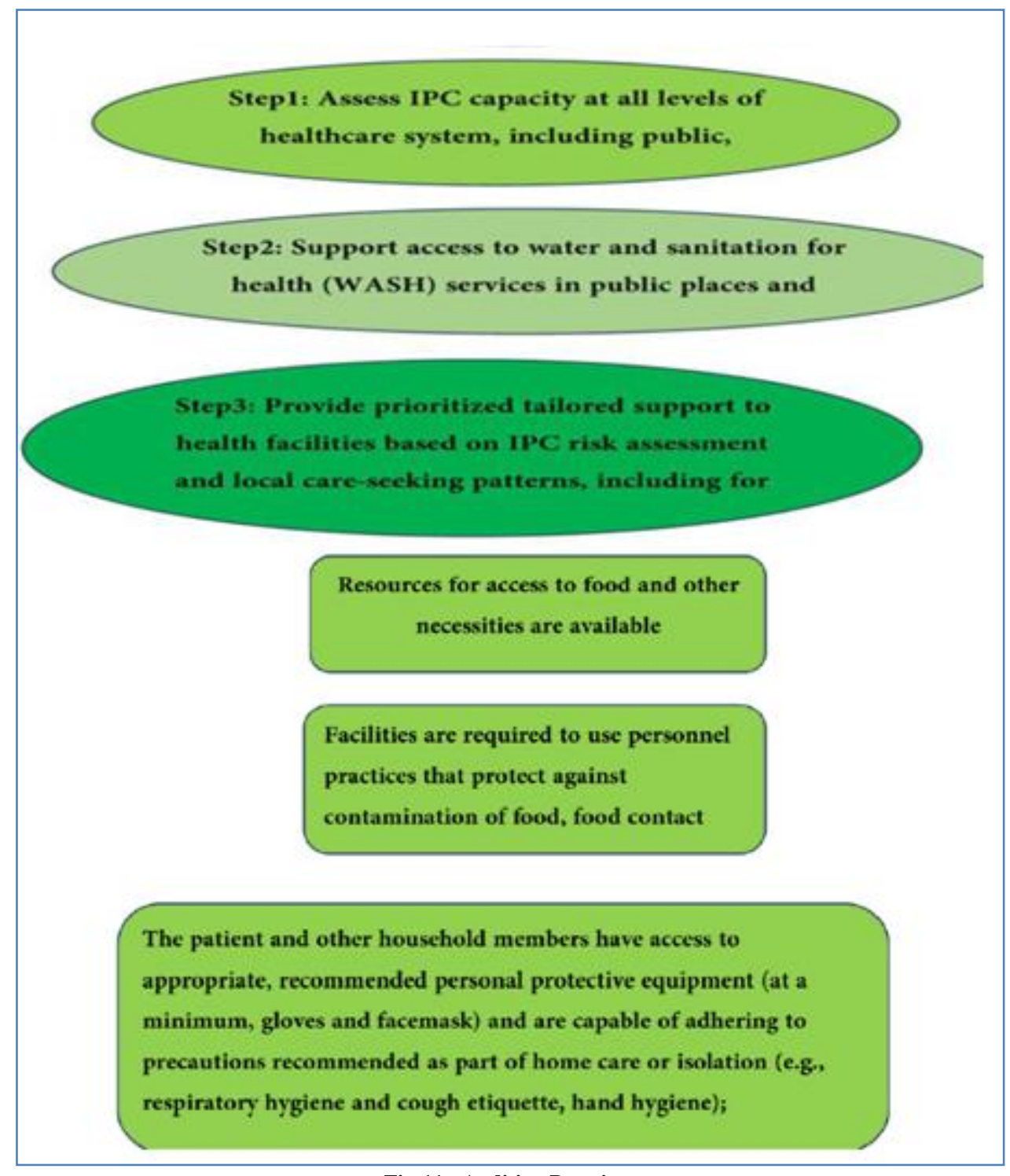

Fig-11: Auditing Practices

\section{Integrating care services}

In line with the developments in discharge planning, policies have also introduced new or extended statutory powers, financial opportunities and penalties to support more integrated discharge pathways. For example, the Health Act 1999 enabled health and social care agencies to pool resources to codeliver rehabilitation services. Similarly, in 2005, delayed discharge grants were made available to social service authorities across England to develop reablement services. In contrast, the Community Care (Delayed Discharges) Act (CCDDA) 2003' addressed the problems of integration by allowing hospitals to claim financial reimbursements from local authorities where they delayed discharge by not providing timely services. Against this backdrop, a variety of integrated services and new care pathways have emerged to support the transition from hospital to community, but in doing so have extended (and made more complicated) the range of services involved in discharge planning[2,9]. 


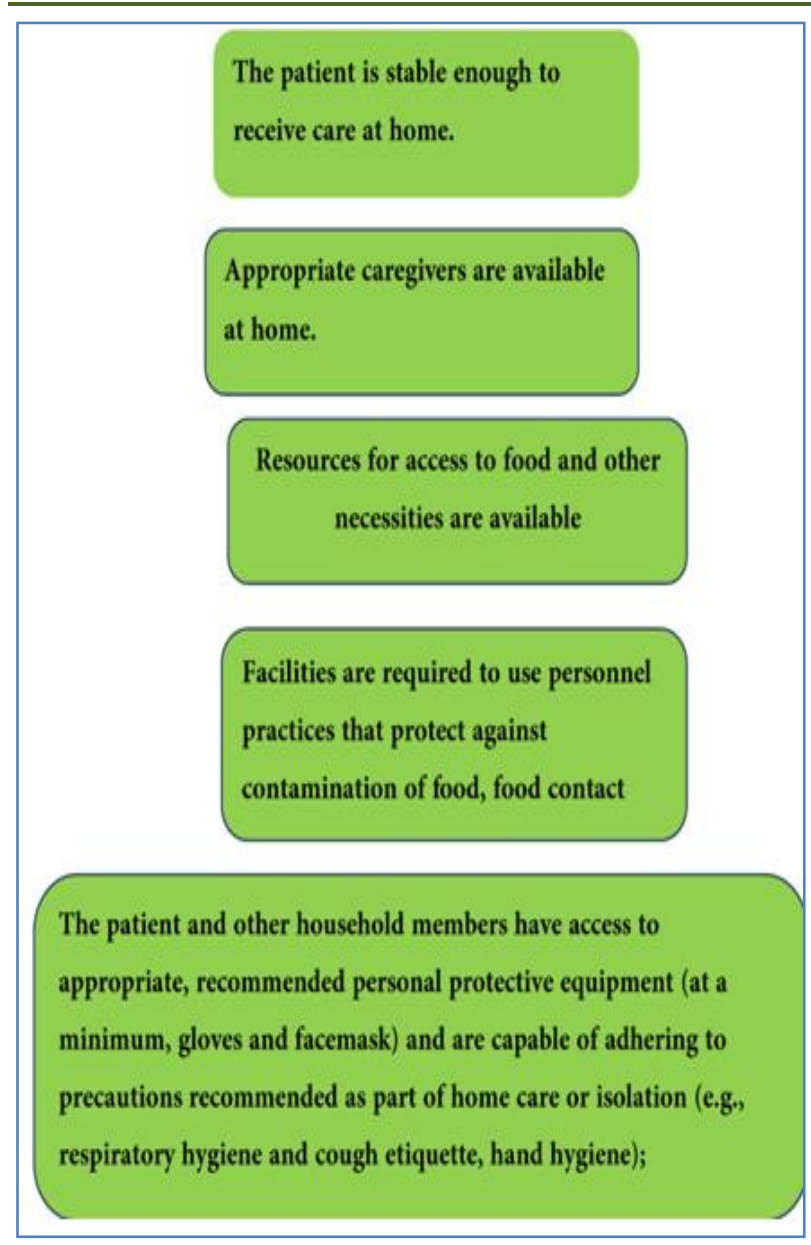

Fig-12: Assessment sustanability of Home care

Multiple sources of evidence suggest that care quality can be suboptimal in, or as a consequence of, hospital discharge. Research highlights a number of common discharge-related risks associated, for example, with the management of medicines, the provision of appropriate health and social care, incomplete tests and scans, the fitting and use of home adaptation, and the risks of falls, infections or sores. The underlying sources of these risks can range from factors related to the patient's condition or comorbidity, to the assessment of patient need, the availability of specialist resources in the community, and wider organizational and cultural factors. Research also suggests that time of day, week or year can also have an impact on discharge planning and quality [3,19].

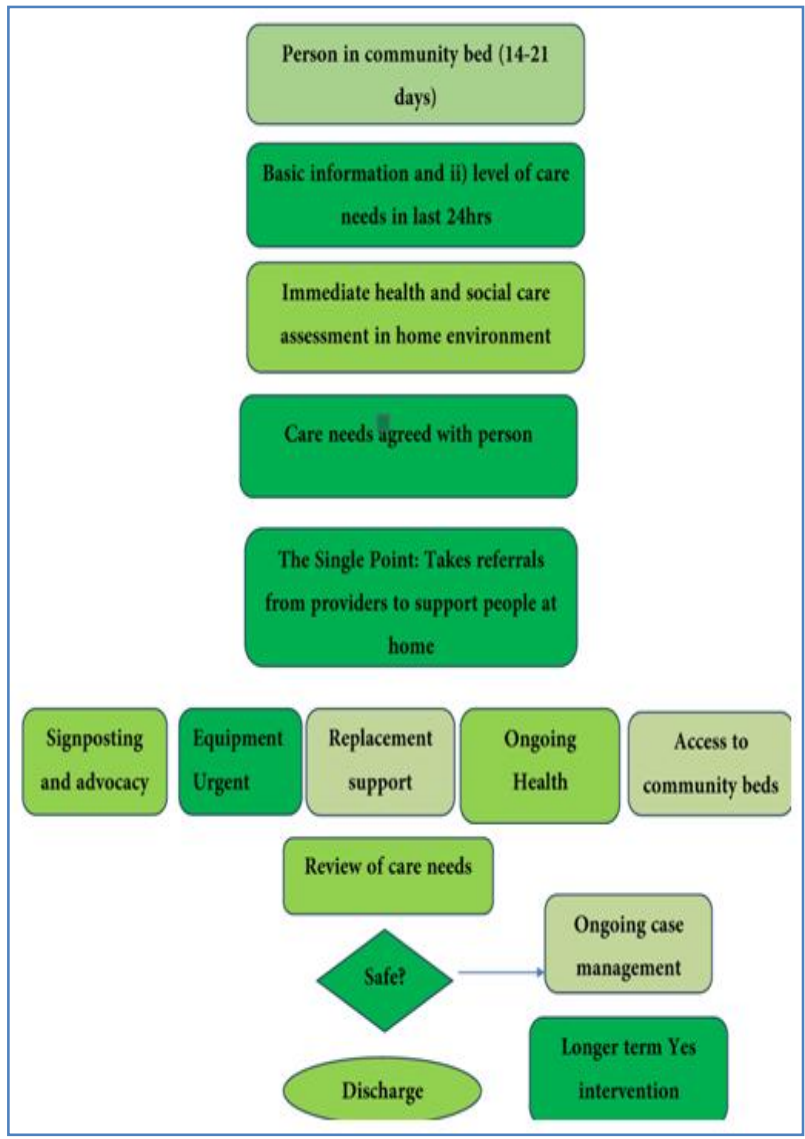

Fig-13: COVID-19 Hospital Discharge Services

\section{Competing interests}

Authors have declared that no competing interests exist.

\section{CONCLUSION}

A protocol for nutritional management in patients infected with COVID-19 has been summarized by this paper. More data are needed to be analysed on the impact of nutritional status and dietary modification on COVID-19.

\section{REFERENCES}

1. Singer P, Blaser AR, Berger MM, Alhazzani W, Calder PC, Casaer MP, Hiesmayr M, Mayer K, Montejo JC, Pichard C, Preiser JC. ESPEN guideline on clinical nutrition in the intensive care unit. Clinical nutrition. 2019 Feb 1;38(1):48-79.

2. McClave SA, Martindale RG, Vanek VW, McCarthy M, Roberts P, Taylor B, Ochoa JB, Napolitano L, Cresci G, ASPEN Board of Directors, American College of Critical Care Medicine. Guidelines for the provision and assessment of nutrition support therapy in the adult critically ill patient: Society of Critical Care Medicine (SCCM) and American Society for Parenteral and Enteral Nutrition (ASPEN). Journal of Parenteral and Enteral Nutrition. 2009 May;33(3):277-316. 
Mohamed F Madi et al., Sch Acad J Biosci, April, 2020; 8(4): 97-110

3. Elia M. Screening for malnutrition: a multidisciplinary responsibility. development and use of the 'malnutrition universal screening tool' ('MUST') for adults. Bapen.org.uk. 2003 [cited 30 January 2016]. Available from: http://www.bapen.org.uk.

4. Mukhopadhyay A, Henry J, Ong V, Leong CS, Teh AL, van Dam RM, Kowitlawakul Y. Association of modified NUTRIC score with 28-day mortality in critically ill patients. Clinical nutrition. 2017 Aug 1;36(4):1143-8.

5. Allard JP, Keller H, Jeejeebhoy KN, Laporte M, Duerksen DR, Gramlich L, Payette H, Bernier P, Vesnaver E, Davidson B, Teterina A. Malnutrition at hospital admission - contributors and effect on length of stay: a prospective cohort study from the Canadian Malnutrition Task Force. Journal of Parenteral and Enteral Nutrition. 2016 May;40(4):487-97.

6. Singer P, Blaser AR, Berger MM, Alhazzani W, Calder PC, Casaer MP, Hiesmayr M, Mayer K, Montejo JC, Pichard C, Preiser JC. ESPEN guideline on clinical nutrition in the intensive care unit. Clinical nutrition. 2019 Feb 1;38(1):48-79.

7. Zhang L, Sun W, Chen L, Wang Q, Liu Y, Zhao S, Li J, Wang Y, Yu L. Clinical Features and a Simple Model for Predicting the Mortality of Coronavirus Disease 2019 Patients on Admission. Available at SSRN 3551386. 2020 Mar 5.

8. Ramesh S, Manimegalai B. Effective Safety Management Practices of an Outsourced Catering Group in a Hospital Kitchen of a Tertiary Care Hospital. International Journal for Advance Research and Development. 2018;3(2):145-8.

9. Ülker V, Erdoğan Ö. Are We Ready for Bioterrorism? Health Personnel were affected by Contaminated Meat Cooked at a Daily Routine Hospital Kitchen. Prehospital and Disaster Medicine. 2019 May;34(s1):s102-.

10. World Health Organization. Home care for patients with Middle East respiratory syndrome coronavirus (MERS-CoV) infection presenting with mild symptoms and management of contacts: interim guidance. World Health Organization; 2018.

11. Kayiwa JT, Nankya AM, Ataliba IJ, Mossel EC, Crabtree MB, Lutwama JJ. Confirmation of Zika virus infection through hospital-based sentinel surveillance of acute febrile illness in Uganda, 2014-2017. Journal of General Virology. 2018 Jul 5;99(9):1248-52.

12. Andersen BM. Food and Beverages. InPrevention and Control of Infections in Hospitals 2019 (pp. 929-942). Springer, Cham.

13. El-Wehedy SE, Darwish WS, Tharwat AE, Hafez AE. Hygienic status of meat served at hospitals and its improvement after HACCP implementation. Japanese Journal of Veterinary Research. 2019;67(1):61-73.

14. Adikari AM, Rizana MF, Amarasekara TP. Food safety practices in a teaching hospital in Sri Lanka. Procedia food science. 2016 Jan 1;6:65-7.

15. Lestantyo D, Husodo AH, Iravati S, Shaluhiyah Z. Safe Food Handling Knowledge, Attitude and Practice of Food Handlers in Hospital Kitchen. Int. J. Public Health Sci. 2017 Dec;6(4):324-30.

16. Carruthers S. Food safety... from paddock to patient. Practical Hydroponics and Greenhouses. 2017 Jan(175) :estantyo D, Husodo AH, Iravati S, Shaluhiyah Z. Hospital Food Hygiene Assurance and the Role of Food Handlers' Perception. Advanced Science Letters. 2017 Apr 1;23(4):3457-60.

17. COVID-19 / Coronavirus - Advice for the General Public March 272020

18. World Health Organization. Coronavirus disease 2019 (COVID-19): situation report, 51.

19. Needling D, Consultations C, Training $\mathrm{MH}$, Massages W, Massage DT, Massage ST, Massage S, Brodie N, Sun WC, Ruben C, Ooi SY. Public Announcement: Coronavirus.

20. Discharge criteria for confirmed COVID-19 cases ECDC TECHNICAL

REPORThttps://www.ecdc.europa.eu/sites/default/f iles/documents/COVID-19-Discharge-criteria.pdf

21. Centers for Disease Control and Prevention. Interim Guidance for Implementing Home Care of People Not Requiring Hospitalization for 2019 Novel Coronavirus (2019-nCoV). Updated Janury 31, 2020.

22. http://www.euro.who.int/en/health-topics/health-e mergencies/coronavirus-covid-19/news/news/2020/ 3/best-practices-for-infection-prevention-and-contr ol,-with-a-spotlight-on-covid-19-countries-share-ex periences. 